\title{
A DIMENSÃO DEMOCRÁTICA DA ELABORAÇÃO DO PROJETO POLÍTICO-PEDAGÓGICO NA EDUCAÇÃ̃ INFANTIL: RELAÇÕES E ESPECIFICIDADES
}

\section{Introdução}

Desde a sanção da constituição de 1988, presenciamos no âmbito educacional brasileiro, importantes transformações decorrentes das lutas dos segmentos ligados à educação, no que tange a reestruturação, financiamento e valorização deste setor. Podemos apontar a implementação do debate sobre gestão educacional democrática, como uma dessas conquistas. Esta tendência tem sido alvo de discussões polarizadas: alguns teóricos defendem que este é um grande passo de democratização e valorização da educação, coerentes com as reformas educacionais, e existe ainda, a crença de ser esta mais uma estratégia governamental para transferir responsabilidades às instâncias e instituições locais. (BARROSO, 2003).

Especulações à parte, convém ressaltar, como afirma Falkembach (in: VEIGA, 2009, p. 134), que:

\footnotetext{
cada momento histórico tem seus processos dominantes que vão se construindo como se fossem uma enxurrada de seu tempo, sintetizando, em sentido, intencionalidades e suas objetivações[...]. Mas eles não eliminam a heterogeneidade dos social. Podem, sim gestar novos arranjos em suas esferas heterogêneas.
}

Amplamente falando, a Gestão Escolar é um termo diretamente ligado à noção de gerenciamento, implicando relações de poder, ou ainda uma política distributiva relacionada à área da educação e suas vertentes, principalmente na parte organizacional dos sistemas de ensino em seus diversos contextos: político, físico, social e financeiro. Quando a gestão escolar pauta-se em relações estabelecidas no âmbito extra-escolar, considerando os processos mais amplos, articulando-se dentro e fora da escola, respeitando e valorizando os agentes envolvidos e os interesses voltados às necessidades reais vividas em cada espaço, esta pode ser chamada de gestão democrática.

Neste sentido, como afirma Pimenta (1993), baseada em fundamentos de uma gestão democrática, a escola deve ser vista ou entendida como instituição social que tem acima de tudo, finalidades político-pedagógicas e a participação na tomada de decisões de toda a comunidade escolar, quesito este, essencial para a promoção de uma educação 
democrática. Cabe a escola democrática e a União, estados ou municípios em conjunto e harmonia buscar construir subsídios que promovam ao cidadão não só o acesso e a permanência, mas aliado a esses fatores, uma educação de qualidade.

Assim sendo, acreditamos ser o Projeto Político-Pedagógico enquanto mecanismo institucional coletivamente elaborado, um importante passo para a consolidação da gestão democrática nas instituições educativas, incluindo as instituições infantis, na medida em que estas ao ganhar cada vez mais proeminência e notoriedade nos últimos planos e metas governamentais, integram-se ao cunho da responsabilidade para com sua organização e finalidades.

\section{A nova LDB : Educação Infantil e democratização do planejamento em foco}

A consolidação da constituição de 1988, suscitou a discussão e aprovação de recursos para a aprovação e implementação da nova Lei de Diretrizes e Bases da Educação Nacional (9394/96), que impõe às instituições de ensino, a elaboração e execução do Projeto Político-Pedagógico, tendo este, como o plano de ações contendo os princípios educativos e ações a serem adotadas pela instituição afim de promover a qualidade no ensino.

Para Gandin (1999), no que concerne o intuito do Projeto Político-Pedagógico de trazer documentadas as diretrizes e o teor filosófico das instituições, a Lei apenas fez tornar obrigatória uma prática que já existente há décadas, mas que, no entanto, não se concretizava da maneira clara e consistente presentes nos debates atuais. Na visão do autor a Lei ganha importância na perspectiva em que torna obrigatório o uso do Projeto enquanto ferramenta, que força a transformação de idéias em ação, algo que comumente não acontece no âmbito educacional.

Analisando o conceito de descentralização ou desresponsabilização do governo atribuído por Dourado (2007) em artigo sobre Políticas e Gestão da Educação no Brasil, podemos constatar que, as reformas educacionais apenas fizeram ficar ainda mais claras, a falta de comprometimento do estado para com a estruturação e provimento de subsídios para o desenvolvimento educacional no país. O ideal contido nas reformas educacionais era o de que, partir da descentralização a escola enquanto instituição poderia reestruturar a organização do trabalho pedagógico, pautando-se em interesses e necessidades presentes na sua comunidade. Porém, conforme aponta Ribeiro (2002), as 
reformas econômicas, sociais e educacionais, movimentadas e consolidadas nas últimas décadas, reafirmam a posição do estado quanto a manutenção de políticas sociais e educacionais voltadas a atender os interesses das classes dominantes, ao passo que, sob o pretexto de trazer ao contexto educacional, o redimensionamento de papéis e a adoção de conceitos administrativos modernos, sequer conseguiu contemplar os preceitos neoliberais nos quais se espelharam:

\begin{abstract}
A Reforma do Estado, e também da Educação, que trazia valores empresariais tais como eficiência, eficácia, gestão da qualidade total, gerência e administração de recursos humanos e materiais são conceitos carregados de interesses, e que não enganam quando usados como se estivessem acima das diferenças de visões e objetivos a serem atingidos. É o caso de perguntar sempre eficácia para quem? Eficiência em relação a quais objetivos? Qualidade total em relação a quais parâmetros? E gerência e administração de recursos humanos e materiais como se não houvesse diferença entre estes dois últimos? Tudo isso em nome de uma racionalidade que leva a quê? Nem sequer respondeu com crescimento econômico, objetivo primeiro do neoliberalismo. ( RIBEIRO, 2002, p. 152. Grifo da autora. )
\end{abstract}

De fato, o redimensionamento das responsabilidades_ governo, estado, municípios e instituições de ensino, ocorreu. Como também vem ocorrendo uma reflexão mais constante e aprofundada a respeito da necessidade de o trabalho pedagógico, estar direcionado a contemplar a diversidade cultural e econômica do país. Conteúdo, a discussão acerca de toda a autonomia propagada pela nova lei educacional continua a ser questionada, na medida em que por si só, não é capaz de garantir a oferta de qualidade na educação. Além da prerrogativa responsabilidade estatal para com o provimento de condições básicas para o desenvolvimento do trabalho pedagógico, autonomia implica em responsabilidade e preparo por parte dos profissionais que atuam nas escolas. Para Rios (apud: VEIGA, 2009, p. 19) o conceito de autonomia na educação está vinculado à noção de liberdade “(...) a liberdade deve ser considerada, também como liberdade para aprender, ensinar, pesquisar e divulgar a arte e o saber direcionados para uma intencionalidade definida coletivamente."

Apesar das falta de unanimidade a respeito do processo de descentralização na educação, os novos moldes do planejamento educacional foram sancionados e prescritos pela governo através da Lei de Diretrizes e Bases da Educação (Lei 9394/96), que estabelece através de seu artigo $9^{\circ}$ que a União tem como responsabilidade a elaboração do PNE - Plano Nacional de Educação. Os artigos seguintes $10^{\circ}$ e $11^{\circ}$ se destinam aos estados e municípios com a obrigatoriedade de constituírem seus sistemas de ensino. 
Finalmente $\mathrm{o}$ artigo $12^{\circ}$ da mesma lei, acrescenta a obrigatoriedade aos estabelecimentos de ensino, de elaborar e executar sua própria proposta

Nas instituições destinadas aos cuidados com a faixa etária de 0 aos 6 anos (creches, pré-escolas, ou centros de educação infantil), tornou-se notória a preocupação quanto ao ato de organizar o trabalho pedagógico, após a inserção da mesma na referida LDB, como etapa inicial da educação básica, ganhando estatuto de direito da população. Em 2001, com a sansão do Plano Nacional de Educação, ficam reforçadas as atribuições das instituições de educação infantil, creches e pré-escolas (de 0 à 6 anos), e sua responsabilidade para com a educação desta faixa etária, bem como, o desenvolvimento de seus princípios educacionais, conforme o item 1.2, no qual constam as diretrizes da educação infantil:

\begin{abstract}
Por determinação da LDB, as creches atenderão crianças de zero a três anos, ficando a faixa de 4 a 6 para a pré-escola, e deverão adotar objetivos educacionais, transformando-se em instituições de educação, segundo as diretrizes curriculares nacionais emanadas do Conselho Nacional de Educação. Essa determinação segue a melhor pedagogia, porque é nessa idade, precisamente, que os estímulos educativos têm maior poder de influência sobre a formação da personalidade e o desenvolvimento da criança. Trata-se de um tempo que não pode estar descurado ou mal orientado. Esse é um dos temas importantes para o PNE. (BRASIL, 2001)
\end{abstract}

Diante disto, ficou ressaltada a responsabilidade de creches e instituições infantis quanto ao desenvolvimento e aprendizagem das crianças, tornando necessária a reflexão sobre os efeitos diretos e indiretos de tal perspectiva na ação docente, e o "reordenamento na sua estrutura funcional e organizacional, bem como a premissa urgente de se pensar o projeto político pedagógico como instrumento norteador das ações" Costa (2003, p.28).

Dado o contexto histórico de constituição das instituições de educação infantil, em especial no âmbito de zero à três anos, sendo o cuidar o foco da ação docente, as premissas constantes no PNE, e especificamente no Referencial Curricular Nacional de Educação Infantil, trouxeram para esta etapa, o caráter não apenas assistencial, mas também o direito à apropriação de cultura e subsídios necessários ao desenvolvimento integral do ser:

A implantação de propostas pedagógicas tornou-se outro desafio à medida em que necessitam estar pautadas na perspectiva de inclusão das crianças de zero a seis anos de idade, em projetos educativos que as contemplem em sua 
diversidade sociocultural e racial. Essa questão está presente não só quando se refere à proposta de uma política nacional de Educação Infantil, considerando-se as diferenças culturais, étnicas, históricas, geográficas, sociais e econômicas de cada região, como quando o foco são projetos pedagógicos específicos a cada instituição com as suas peculiaridades administrativa, funcional e técnica, trabalhando com crianças e famílias também singulares e únicas, como grupos e como pessoas. (COSTA, 2003, p. 50)

$\mathrm{Na}$ tentativa de promover a esperada integração entre o cuidado, o desenvolvimento integral do ser, o direito à infância e à cidadania, previstos pela atual legislação, acreditamos, que um dos principais caminhos, é através da construção participativa do Projeto Político-Pedagógico. É no momento de sua construção que devem ser colocadas em pauta e debatidas as especificidades que caracterizam a educação infantil, bem como serem diagnosticadas todas as questões práticas prementes de solução, e que configuram a necessidade de o Projeto ser elaborado pela comunidade escolar conforme as suas necessidades, sendo portanto, único por que está diretamente voltado a atender uma realidade sócio-cultural específica, porém flexível, conforme veremos a seguir.

\section{O Projeto Político Pedagógico na Educação Infantil e a necessidade de reflexão sobre suas especificidades}

Na definição de Vasconsellos (2010, p. 169), o Projeto Político-pedagógico pode ser entendido como:

[...] o plano global da instituição. Pode ser entendido como a sistematização nunca definitiva, de um processo de Planejamento Participativo, que se aperfeiçoa e se concretiza na caminhada, que define claramente o tipo de ação educativa que se quer realizar. É um instrumento teórico- metodológico para a intervenção e mudança da realidade. É um elemento de organização e integração da atividade prática da instituição neste processo de transformação.

Ainda conforme o autor, é considerado um projeto, por se manifestar através de um conjunto de antecipações, projeções das metas a serem alcançadas. É também político, devido a sua construção, que deve ser pautada na dimensão participativa e abrangente a todos os aspectos que compõem o cenário escolar: corpo pedagógico, funcionários, alunos e suas famílias.

No contexto das instituições destinadas aos cuidados e educação de crianças pequenas, o ato da construção deste "plano global de ações" constitui-se numa tarefa 
mais sensível em comparação aos demais níveis de ensino. Um dos fatores que contribuem para este desafio, é o de que a contextualização histórica na qual foram constituídas as instituições infantis, pautadas na dualidade entre o ensino preparatório paras os anos iniciais do primeiro grau e o conjunto de cuidados assistenciais visando a oferta de condições básicas de higiene e alimentação, constituiu ao longo de sua história, uma abordagem dicotômica em relação os atos de cuidar e educar (BRASIL, 2006, p. 17).

Visualizando a questão de modo mais amplo, para além do objeto de estudo deste artigo, teremos o seguinte quadro: a educação infantil enquanto uma modalidade de ensino relativamente recente na qual o cuidado, a educação e o direito à infância devem estar integrados, é também o contraditório campo constantemente "sacudido" por variadas teorias de ensino-aprendizagem, bem como por políticas visando a qualidade, mas principalmente, a amplificação de sua oferta, porém secundarizando a importância de recursos materiais e humanos adequados para tanto, e conseqüentemente, promovendo a inversão daquilo que é o seu propósito:

\begin{abstract}
A caracterização da instituição de educação infantil como lugar de cuidado-eeducação, adquire sentido quando segue a perspectiva de tomar a criança como ponto de partida para a formulação das propostas pedagógicas. Adotar essa caracterização como se fosse um dos jargões do modismo pedagógico, esvazia seu sentido e repõe justamente o oposto do que se pretende. A expressão tem o objetivo de trazer à tona o núcleo do trabalho pedagógico conseqüente com a criança pequena. Educá-la é algo integrado ao cuidá-la. ( KUHLMANN, 1999, p.60, grifo do autor)
\end{abstract}

Além destes aspectos que acabam por se constituírem como entraves para o planejamento de ações pedagógicas qualitativas, ainda existe a questão da massificação de Projetos norteadores para as instituições, através das instâncias encarregadas de seu gerenciamento. Conforme a LDB o Projeto Político Pedagógico, ainda que seja de autoria das instituições de ensino, deve estar em consonância com propostas educacionais e assistenciais das instâncias superiores, no caso da educação infantil, as secretarias municipais de educação compõem esta supervisão imediata. Nestas circunstâncias, não é raro suceder de as próprias mantenedoras das instituições infantis elaborarem juntamente ao regimento escolar das mesmas, roteiros das propostas pedagógicas a serem seguidas pelas instituições de maneira generalizadora, resultando assim numa desconsideração do diagnóstico da realidade sócio-cultural de cada instituição. 
É preciso que fique clara a distinção entre o Projeto Político Pedagógico da escola $[\cdots]$ e o Regimento Escolar, que é uma exigência legal para o funcionamento da escola. [] De acordo com a legislação em vigor, a elaboração de ambos é de competência da escola. O que se espera é que o regimento possa ser feito a partir do Projeto, qual seja, ter os parâmetros e os princípios do Projeto como referência para o detalhamento administrativo e jurídico (o que nem sempre é possível, pelo menos no todo, em função de normas e diretrizes exteriores à escola).

(VASCONSELLOS, p. 74, 2010)

Algumas instituições optam por "embutir" o regimento escolar no Projeto. No caso da educação infantil, o regimento contém as mesmas especificações legais dos demais níveis de ensino, tais como números de turmas, seriação ou grupos, horários, atribuições dos funcionários, administração financeira, etc. O importante, como já foi citado, é que a elaboração do regimento decorra em adequação com o Projeto anteriormente redigido, no qual já constam os princípios educativos e as estratégias a serem seguidas, e não ao contrário! Destacamos esta questão por que, especialmente na educação infantil, ocorre uma tradição em moldar o tempo, os instrumentos, e o espaço dedicado ao desenvolvimento da criança, e da infância, promovendo assim uma aceleração para que cumpram-se as "regras" contidas no Regimento Escolar, pois existe a tendência em tê-lo como o carro-chefe das rotinas nestes espaços. Segundo Barbosa (2000, p. 234):

\begin{abstract}
A (re)invenção do cotidiano, na escola infantil, depende das possibilidades de os adultos responsabilizarem-se pelo seu próprio tempo, romperem com o tédio da repetição, diminuírem o stress de fazer tudo igual, criando um tempo diverso e diversificado, um tempo que ouça as crianças e os próprios educadores, tudo o que elas têm de inovador, de criativo. Usar o tempo com a clareza possível a respeito dos fatores que nos fazem realizar as coisas de um modo ou de outro.[...] É necessário fazer uma contínua crítica radical aos processos sociais de regulação duvidando dos saberes instituídos, tentando pensar, algo que não se pensava antes e perceber de modo diferente o que se vê como algo natural. É preciso, como dizem alguns antropólogos, estranhar o conhecido e conhecer o estranho (BARBOSA, 2000 grifo da autora)
\end{abstract}

É preciso, como alerta sabiamente a autora, questionar as rígidas regras que assolam o contexto das creches e demais instituições infantis, tais como horários de sono, de alimentação, de brincar. Se reconhecemos as crianças como sujeitos dotados de capacidade de aprendizado, de cultura, de história, de características e vontades individuais, é incoerente querer que num grande grupo, todas sintam sono ao mesmo 
tempo, ou que façam suas refeições num mesmo ritmo, ou até mesmo que tenham que permanecer constantemente atreladas a atividades, sem que possam também ter o direito de estarem ociosas eventualmente ao longo do dia, afim de decidirem por elas mesmas o que querem fazer ou do que querem ou não brincar (lembrando que, o inverso, ou seja o excesso de ociosidade seria igualmente prejudicial).

Reconhecemos que, as mudanças dessas postulações geridas a partir da elaboração do Projeto não são construções simples, e muitas vezes encontra entraves e falta de interesse por parte alguns atores que compõe o contexto, mas é imprescindível que haja o debate e também um esforço e incentivo mútuo entre os envolvidos, para que uma vez decididas, não permaneçam apenas no plano das idéias.

Considerar a construção do Projeto Político-Pedagógico na Educação Infantil como um plano de ações diretamente ligado às peculiaridades caracterizadoras da faixa etária, respeitando assim o seu tempo, a sua liberdade criadora e expressiva, o contexto cultural e econômico ao qual está inserida, implica um trabalho descentralizado, coletivo, no qual a problematização, o diálogo, as tomadas de decisões e estratégias são incorporados como algo inerente ao trabalho pedagógico de qualidade.

Na visão de Santiago (in: VEIGA,2009), a expressão Projeto PolíticoPedagógico tornou-se usual nas instituições de ensino nos últimos anos, sem que, na prática pedagógica, pudessem ser observados os esforços dos educadores no sentido de promover a derrota da dualidade existente entre estas dimensões, política e pedagógica, e que constituem uma das razões de não serem atingidos os objetivos educacionais de promoção da aprendizagem e exercício da cidadania.

Neste sentido, é essencial segundo a autora, que os professores estejam atentos ao fato de que, a construção do projeto escolar prescinde de responsabilidade para com a sua formação, que esta aconteça de forma adequada e atualizada, desta forma os educadores disponibilizarão da clareza e o discernimento necessários para identificar quais concepções teóricas a respeito de sociedade, homem, aprendizagem e ensino, devem ser incorporadas afim de que se promova a transformação da realidade específica dos sujeitos que compõem a comunidade escolar. É a partir do Projeto PolíticoPedagógico que surgem também os pressupostos norteadores da proposta curricular adotada pelos educadores para o seu trabalho com o grupo de alunos. Isto só ocorrerá, no entanto, adotando-se a consciência da importância de amplos e consistentes diálogos a respeito das práticas a serem adotadas. Essas discussões vão desde a análise das diferentes teorias pedagógicas que compõem o cenário educacional, até a tomada de 
decisões sobre a aplicabilidade de comportamentos e estratégias.

Conforme indica Sarmento (2005, p.25), “a infância é, simultaneamente uma categoria social, do tipo geracional, e um grupo social de sujeitos ativos, que interpretam e agem no mundo". Repensar a maneira como são planejadas as ações pedagógicas nas instituições que atendem as crianças pequenas implica diretamente na reflexão sobre as concepções nas quais estão pautadas as noções de ensino e aprendizagem, de infância, de educação com vistas à promoção da justiça social. Conseqüentemente, repensar a construção do Projeto, sugere uma reflexão conjunta sobre o que ensinar, como ensinar, quais subsídios humanos e materiais providenciar, ou seja, não se resume apenas ao trabalho executado dentro da sala de aula da creche, mas envolve todos os demais setores institucionais.

Considerando a tomada de consciência de que o modelo ao qual a educação infantil foi constituída dicotomizando atos de cuidado e postulação de conteúdos programáticos mimetizados aos das séries inicias, não contemplam os aspectos infantis de desenvolvimento integral de aprendizagem e vivência sadia da infância, Kuhlmann (in: FARIA; PALHARES, 1999, p. 57) aponta (após a então recente LDB) o possível caminho para a mudança:

\footnotetext{
Se na nova Lei educacional, a educação básica envolve a educação infantil, o ensino fundamental e o ensino médio, apenas o ensino fundamenta é obrigatório, destinado a todas as crianças brasileiras a partir do sete anos de idade. A educação infantil é de outra ordem pois não se destina à todos. Assim, seria um equívoco ingressá-la nos moldes do ensino fundamental, que lhe sucede uma perspectiva preparatória, propedêutica. Se a criança vê ao mundo e se desenvolve em interação com a realidade social, cultural e natural, é possível pensar uma proposta educacional que lhe permita conhecer esse mundo, a partir do profundo respeito por ela. Ainda não é momento de sistematizar o mundo para apresentá-lo à criança: trata-se de vivê-lo, de proporcionar-lhe experiências ricas e diversificadas.
}

Nesta tarefa de propiciar tais experiências ricas e diversificadas, podemos entender os ambientes que compõem a educação infantil, creches e pré-escolas, como um valioso espaço no qual os sujeitos interagem, trocam eventualmente seus papéis, colaboram, cedem, permitem-se transgredir, inovar e aprender com os erros e as diferenças. É neste ambiente heterogêneo e maleável, que se põe em prática, se efetivam e consolidam práticas propiciadoras da infância rica de aprendizado através de experiências libertadoras e prazerosas, que são conseqüência de planejamento intencional e coletivamente elaborado, a partir das concepções de infância, criança e aprendizado, 
contidas no Projeto Político-Pedagógico.

\section{Família e Escola: Uma parceria de sucesso na democratização do PPP}

A educação infantil compreendida como etapa inicial da escolarização no ensino básico compreende a acolhida, os cuidados e a educação para a população da primeira infância, pressupõe que, o trabalho desenvolvido nestas instituições possui especificidades diferentes dos demais níveis de ensino.

A criança inclusa desde o berço nas instituições cuidadoras, inevitavelmente passa a integrar este cenário e enxergá-lo como uma extensão do seu próprio lar, sendo que, em especial nas instituições públicas, esta inserção acontece precocemente em virtude do caráter amparatório que as creches exercem para a população carente. A longa jornada diária enfrentada pelos pequenos, desde os primeiros meses de vida, faz com que estes espaços tornem-se uma extensão do próprio lar. A criança habitua-se a perceber os profissionais que lidam com ela diariamente como integrantes indissociáveis à sua vida, à sua história, ao seu desenvolvimento. Simultaneamente, transfere para o ambiente escolar, traços de sua cultura, de sua convivência familiar, de seus hábitos. Família e escola são, portanto, as primeiras "redes" sociais de mediação e regulação às quais a criança está subordinada, conforme aponta Dessen (2007, p. 27):

\footnotetext{
A escola e a família compartilham funções sociais, políticas e educacionais, na medida em que contribuem e influenciam a formação do cidadão (Rego, 2003). Ambas são responsáveis pela transmissão e construção do conhecimento culturalmente organizado, modificando as formas de funcionamento psicológico, de acordo com as expectativas de cada ambiente. Portanto, a família e a escola emergem como duas instituições fundamentais para desencadear os processos evolutivos das pessoas, atuando como propulsoras ou inibidoras do seu crescimento físico, intelectual, emocional e social.
}

Neste contexto, mostra-se inegável o papel fundamental da participação da família no ato da construção do Projeto Político-Pedagógico. Esta participação terá importantes e positivas inferências desde o âmbito da elaboração curricular, até as questões administrativas.

Sendo o mote educacional do trabalho dirigido aos pequenos, o desenvolvimento de suas habilidades motoras, afetivas e cognitivas, ressaltando as peculiaridades da primeira infância como a capacidade de imaginação, criação, espontaneidade e interação, concomitantemente à ações de cuidados e assistência, é contraditório basear 
as ações em propostas curriculares que não incluam a interação e participação ativa dos pais e familiares nessa empreitada. É necessário refletir sobre a abertura de espaços para que estas trocas possam ocorrer, de modo que não se retenham apenas aos poucos minutos em que pais e professoras estabelecem contato, ou seja, na entrada e saída das crianças. Esta abertura, pode ser discutida junto às famílias e ser elencada no conjunto de ações transformadoras do Projeto Político-Pedagógico elaborado de maneira participativa e que, desta forma, possam ser ocasiões em que o diálogo não se baseie apenas nas questões assistenciais, mas que estas estejam intrinsecamente ligadas à intenção mútua, da família e da escola, de efetivação de todos os pressupostos qualitativos que norteiam a educação infantil.

As discussões coletivas acerca de questões organizacionais e administrativas se fazem presentes no projeto de qualidade na educação infantil, haja visto que, implicam diretamente no cotidiano das famílias, em especial as das camadas mais carentes. É importante, por exemplo, que pais e responsáveis possam ter abertura para opinar e modificar horários de reuniões, conforme as suas necessidades, bem como dialogar sobre as melhores maneiras de poderem colaborar com a promoção de eventos comuns nos centros de educação infantil (festas comemorativas, homenagens, eventos para angariar fundos), sem que isto configure-se para estas famílias - em especial as mais pobres - em circunstâncias nas quais sentem-se coagidas ou rechaçadas.

Outro ponto importante a ser debatido e elencado nas diretrizes do Projeto, diz respeito à maleabilidade de horários e o incentivo ao acesso das mães à sala de aula no período de adaptação das crianças à creche. No início do ano, a insegurança e o choro são comuns aos pequenos, em especial nos momentos de chegada à instituição, nestes momentos é importante que não apenas as crianças possam ser acolhidas, como também as mães, pais ou responsáveis sintam-se à vontade para acompanhar seus filhos e tornar este início mais confortável para todos os envolvidos conforme indica o RCNEI (1998).

Ressaltamos ainda, pensando na elaboração participativa do Projeto PolíticoPedagógico, a importância do envolvimento de toda a comunidade escolar na constituição das APP's (associação de pais e professores). É indiscutível a relevância destas organizações para o desenvolvimento das instituições, nas tomadas de decisões e planejamento de ações com vistas à melhorias às escolas, bem como, para a integração entre pais e professores no intuito de promover o ensino de qualidade. Nossa interrogação, no entanto, diz respeito ao modo como esses conselhos são eleitos, sobre os membros que os constituem (em sua maioria professores), bem como, a pouca 
participação da grande massa de pais e responsáveis que, sequer chegam a inteirar-se das ações ocorridas nestes segmentos durante o ano letivo. Em um recente artigo relatando sua pesquisa quanto ao planejamento democrático no município de Blumenau, Rocha (2006, p. 07) constata que:

\begin{abstract}
É preciso deixar de lado as concepções equivocadas que temos em torno da democratização da escola pública e, acionarmos mecanismos concretos e práticos de estreitamento de relações entre comunidade e escola. Entendemos que os colegiados escolares como as APP's, possuem forças ímpares nesse processo de estreitamento. Nas Atas em que pesquisamos, constatamos que a APP não possui uma função diferente de outras APP's que conhecemos. Em nenhum momento notamos preocupações com questões relativas ao ato pedagógico. O que constatamos, foi uma APP preocupada em gerar recursos financeiros para manter a escola funcionando. Nesse momento, de nosso estudo, percebemos que a gestão democrática e participativa materializava-se nas questões inerentes as festas comunitárias, rifas, bingos e outros mecanismos geradores de recursos financeiros. Ações como essas, esvaziamse em si mesmas. Não visam os desejos comunitários. Não configuram democracia e participação no espaço escolar.
\end{abstract}

Na educação infantil, não raramente observa-se a eleição das APP's apenas como cumprimento de uma ação burocrática, haja visto, que a legislação educacional assim o impõe, não havendo a interação entre os todos envolvidos e a descentralização nas tomadas de decisões, que são as principais estratégias destas organizações. Neste contexto, ao invés de promover um elo fortalecedor e transformador entre a escola e a comunidade, as associações assim administradas acabam por restringir a participação da maior parte das famílias apenas ao recebimento de informações desta ou daquela ação que está sendo tomada (em geral objetivando apenas o levantamento de recursos financeiros), desestimulando a participação coletiva na organização e efetivação de melhorias na promoção da educação de qualidade, e enfraquecendo o potencial transformador que está contido nestes conselhos.

\title{
Considerações Finais
}

O artigo teve por objetivo propor a reflexão sobre os aspectos que caracterizam a construção participativa do Projeto Político-Pedagógico, bem como as peculiaridades que devem ser observadas no âmbito da educação infantil, no momento da elaboração do documento. O Projeto como o abordamos, quando construído e utilizado como instrumento capaz de consolidar e organizar as ações dentro de uma instituição de ensino, possui direta e importante relevância no cotidiano destas organizações. 
A educação infantil, enquanto modalidade de ensino recentemente reconhecida pelas instâncias responsáveis pelo gerenciamento da educação no Brasil, ainda trilha um caminho repleto de suposições e algumas constatações à respeito do ideal que se deseja atingir quanto ao trabalho realizado no interior de creches e pré-escolas, responsáveis pela tarefa de garantir simultaneamente, os cuidados e o oferecimento de condições para o desenvolvimento integral das potencialidades cognitivas, motoras e afetivas das crianças menores de seis anos.

Nesta caminhada, a integração de elementos e diretrizes que antes pertenciam ou eram exigidas apenas aos outros níveis de ensino, passam inevitavelmente a ser solicitada na organização curricular e administrativa da educação infantil, entre eles a elaboração do Projeto Político-Pedagógico. No entanto, a todo momento há que haver a consciência em unanimidade de que o PPP na educação infantil possui diversos "pormenores", que devem ser lavados em conta no ato de sua elaboração.

$\mathrm{Na}$ educação infantil, considerando ser as crianças na mais tenra idade a sua clientela, esta elaboração conjunta deve ser encarada de modo ainda mais sensível e comprometido. É preciso que todos os envolvidos na tarefa diária de cuidar e educar os pequenos, estejam cientes de que, este público possui características que prescindem uma maior flexibilidade com relação às rotinas à que são submetidos durante sua estadia nas creches e demais instituições infantis. Cabe aos educadores, comprometerem-se com a sua formação, sendo esta contínua, atualizada e coerente com a sua prática para então, desenvolverem a criticidade e capacidade de discernimento necessários à construção do Projeto Político-Pedagógico.

Em tempo, destacamos as polarizações às quais estão sujeitas as APP's no contexto da educação infantil. Para que estes estigmas possam ser superados, acreditamos no potencial transformador da descentralização dos poderes, e da interação entre a instituição e à comunidade, afim de que, conhecedores do trabalho que é realizado no interior das creches, esses conselhos constituíam-se em parcerias no fortalecimento do movimento em prol do ensino de qualidade.

A construção democrática dos Projetos nas creches abre espaço para a discussão e solucionamento conjunto de importantes questões que refletem diretamente no bemestar das crianças, famílias, profisssionais da educação e demais funcionários destas instituições, bem como na elaboração de um currículo capaz de proporcionar à criança, os subsídios necessários para o desenvolvimento de suas habilidades, sem haver detrimento quanto ao seu direito à infância. 


\section{Referências Bibliográficas}

BARBOSA, Maria Carmen S.; FARIA, Ana Lúcia G. Por amor \& por força: rotinas na educação infantil. 2000. 283 f. Tese (Doutorado em Educação)- Universidade Estadual de Campinas, Faculdade de Educação. Campinas, 2000.

BARROSO, João. O reforço da autonomia das escolas e a flexibilização da gestão escolar em Portugal. In: FERREIRA, Naura S. C. (org.). Gestão democrática da educação: atuais tendências, novos desafios. 4. ed. São Paulo: Cortez, 2003. p. 11-32.

BRASIL. Lei de Diretrizes e Bases da Educação $\mathbf{n}^{\circ}$ 9.394, de 1996. Disposições Constitucionais Lei $n^{\circ}$ 9424, de 24 de dezembro de 1996. Brasília, DF, 1998. Disponível em: <http://bd.camara.gov.br/bd/bitstream/handle/bdcamara/2762/ldb_5ed.pdf?sequence =1 > Acesso em: 17 mai. 2011.

Ministério da Educação e do Desporto. Secretaria da Educação Fundamental. Referencial Curricular Nacional para Educação Infantil. Brasília: MEC/SEF, 1998.

Plano Nacional de Educação. Brasília: MEC, 2001. Disponível em: <http://www.adusp.org.br/arquivo/PNE/pnemec.pdf > Acesso em: 17 mai. 2011.

COSTA, Selma F. O projeto político-pedagógico nas instituições de atendimento assistencial a crianças de zero a seis anos. Terra e Cultura: Londrina, n.36, p.27-38, 2003.

Disponível em: <http://web.unifil.br/docs/revista_eletronica/terra_cultura/36/Terra\%20e\%20Cultura_36 -4.pdf> Acesso em: 14 mai. 2011.

DESSEN, Maria A.; POLONIA, Ana da C. A Família e a escola como contextos de desenvolvimento humano. Ribeirão Preto: Paidéia, n.17, p. 21- 32 , mai./jun.2007.

FALKEMBACH, Elza M. F. Planejamento Participativo: Uma maneira de pensá-lo e encaminhá-lo com base na escola. In: VEIGA, Ilma P. Da (Org.). Projeto políticopedagógico: Uma construção possível. 26. ed. Campinas: Papirus, 2009. p. 131-142.

GANDIN, Danilo; GANDIN, Luís Armando. Temas para um projeto políticopedagógico. Petrópolis: Vozes, 1999.

KUHLMANN Jr., Moysés. Eucação Infantil e Currículo. In: FARIA. Ana Lúcia G. De; PALHARES. Mariana S. (orgs.). Educação Infantil pós-LDB: rumos e desafios. Editora UFSCar: Florianópolis, 1999. p. 51-66.

LUCE, Maria Beatriz; MEDEIROS, Isabel Letícia Pedroso de. Gestão Escolar Democrática: concepções e vivências. Porto Alegre: Editora UFRGS, 2006.

PIMENTA, Selma G. Questões sobre a organização do trabalho na escola.16. ed. São Paulo: Idéias, p. 78-83, 1993. 
RIBEIRO, Maria R. D. Uma perspectiva histórica da descentralização da educação177 f. Dissertação (Mestrado em Educação). Universidade Estadual de Campinas. 2002 Disponível em: http://www.bibliotecadigital.unicamp.br/document/?code $=\mathrm{vtl} 000259085 \& \mathrm{fd}=\mathrm{y}$ Acesso em : 15 de Jan./ 2012.

ROCHA, Manoel J. F. A associação de professores e a gestão democrática na escola pública. UNIrevista: [S.1], Vol.1, $\mathrm{n} \square<2, \quad$ p.1-10, 2006. Disponível em: $<$ http://www.unirevista.unisinos.br/_pdf/UNIrev_Rocha.pdf $>$ Acesso em: 17 mai. 20011.

SARMENTO, Manuel J. Crianças: educação, culturas e cidadania activa. Refletindo em torno de uma proposta de trabalho. Perspectiva: Florianópolis, v.23, n.1, p. 17-40, jan./jul. 2005.

VASCONSELLOS, Celso dos S. Planejamento: projeto de ensino-aprendizagem e projeto político-pedagógico. 16. ed. São Paulo: Libertad, 2006.

VEIGA, Ilma P. Projeto Político Pdeagógico na Escola. Uma construção Possível. 26 Edição. Campinas: Papirus, 2009. 